\section{Microscopy}

\section{Coming Events}

2019

PITTCON Conference \& Expo 2019

March 17-21, 2019

Philadelphia, PA

https://pittcon.org

ACS Spring Meeting: Chemistry for New Frontiers

March 31-April 4, 2019

Orlando, FL

www.acs.org/content/acs/en/meetings/

html?sc=meetings_1800815 mtg \%200R19 od

FOM2019: Focus on Microscopy 2019 April 14-17, 2019

London, UK

www.microbeamanalysis.eu/events/

event/57-fom2019-focus-on-microscopy-2019

MRS Spring Meeting \& Exhibit

April 22-26, 2019

Phoenix, AZ

www.mrs.org/spring2019

PICO 2019 - Frontiers of Aberration Corrected Electron Microscopy May 5-9, 2019

Kasteel Vaalsbroek, Netherlands

www.er-c.org/pico2019/about.htm

EMAS 2019 - Modern Developments and Applications in Microbeam Analysis

May 19-23, 2019

Trondheim, Norway

https://www.microbeamanalysis.eu

Microscopy \& Microanalysis 2019

August 4-8, 2019

Portland, OR

www.microscopy.org

\section{0}

Microscopy \& Microanalysis 2020

August 2-6, 2020

Milwaukee, WI

www.microscopy.org

\section{1}

Microscopy \& Microanalysis 2021

August 1-5, 2021

Pittsburgh, PA

www.microscopy.org

\section{2}

Microscopy \& Microanalysis 2022

July 31-August 4, 2022

Portland, OR

www.microscopy.org

\section{3}

Microscopy \& Microanalysis 2023

July 24-28, 2023

Minneapolis, MN

www.microscopy.org

\section{4}

Microscopy \& Microanalysis 2024

July 28-August 1, 2024

Cleveland, $\mathrm{OH}$

www.microscopy.org

More Meetings and Courses

Check the complete calendar near the

back of this magazine.

\title{
Combining Microscopies Allows Molecular Contrast at Nanoscale Resolution
}

\author{
Stephen W. Carmichael \\ Mayo Clinic, Rochester, MN 55905 \\ carmichael.stephen@mayo.edu
}

Neural circuits across the brain are composed of structures that vary in size about ten million-fold. No one imaging modality can examine all the significant structures across that span. Electron microscopy (EM) excels at looking at the smallest structures, but confocal fluorescence microscopy can image the larger structures with labels to yield information about the molecular composition of the structures. Authors Ruixuan Gao, Shoh Asano, and Srigokul Upadhyayula, led by Nobel Laureate Eric Betzig and neuroscientist Edward Boyden, combined two imaging modalities that not only covered this huge range of size differences, but also identified the molecular constituents of the specimen, such as the proteins, across the range [1].

One of the modalities they used was expansion microscopy (ExM), which was reviewed in this column in 2015 (Microscopy Today, 23(3) (2015) 8-10). Basically this technique involves adding a water-absorbent polymer gel to preserved tissue. When transferred from a saline solution to pure water, the polymer swells, stretching the tissue approximately four-fold. The imaging relies on fluorescent tags that attach specifically to proteins in cells and tissues and also to the surrounding gel. The proteins are digested to leave the fluorescent molecules exactly in place, and the relative positions between these molecules are maintained after the swelling.

The expanded specimen was imaged by Gao et al. using lattice light-sheet microscopy (LLSM), which was also reviewed in this column (Microscopy Today, 23(1) (2015) 8-10). Briefly, this technique sweeps an ultrathin layer of light through the tissue. By using a less intense light than is required for other methods, the beam can linger on the sample while not bleaching the fluorescence or obscuring part of the image. Since it is relatively fast, LLSM illuminates a whole plane at one time rather than a single spot. It could gather enough information to image the entire

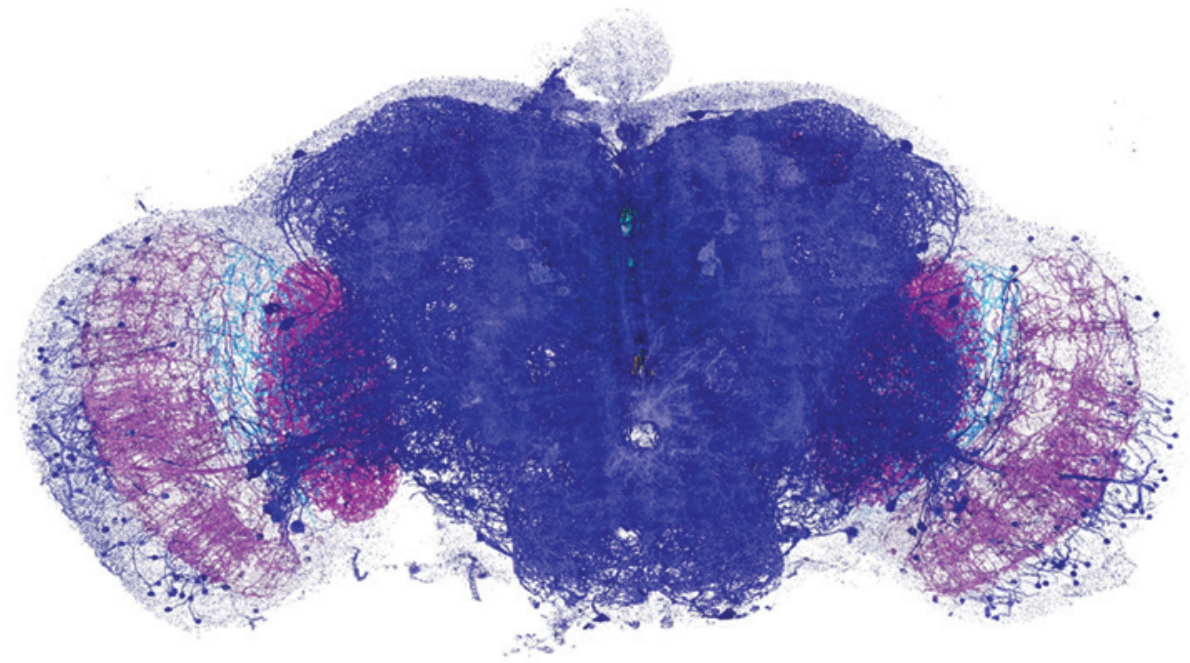

Figure 1: Dopaminergic neurons and the associated presynaptic sites across an adult fruit fly brain, color-coded by brain regions. Image width $=660 \mu \mathrm{m}$. 


\section{EMS has ith...}

Your one-stop shop for all things Materials Science

LAPPING \& POLISHING EQUIPMENT \& SUPPLIES, WAFER CLEAVING SYSTEMS \& TOOLS, HOLDERS, MOUNTS, \& SUPPLIES FOR ATM, SEM, TEM, \& FIB, MOUNTING,

EMBEDDING, \& SECTIONING SUPPLIES, VACUUM

EQUIPMENT \& ACCESSORIES, CALIBRATION STANDARDS \& SPECIMENS, MICRO \& MINI TOOLS, AND MORE...

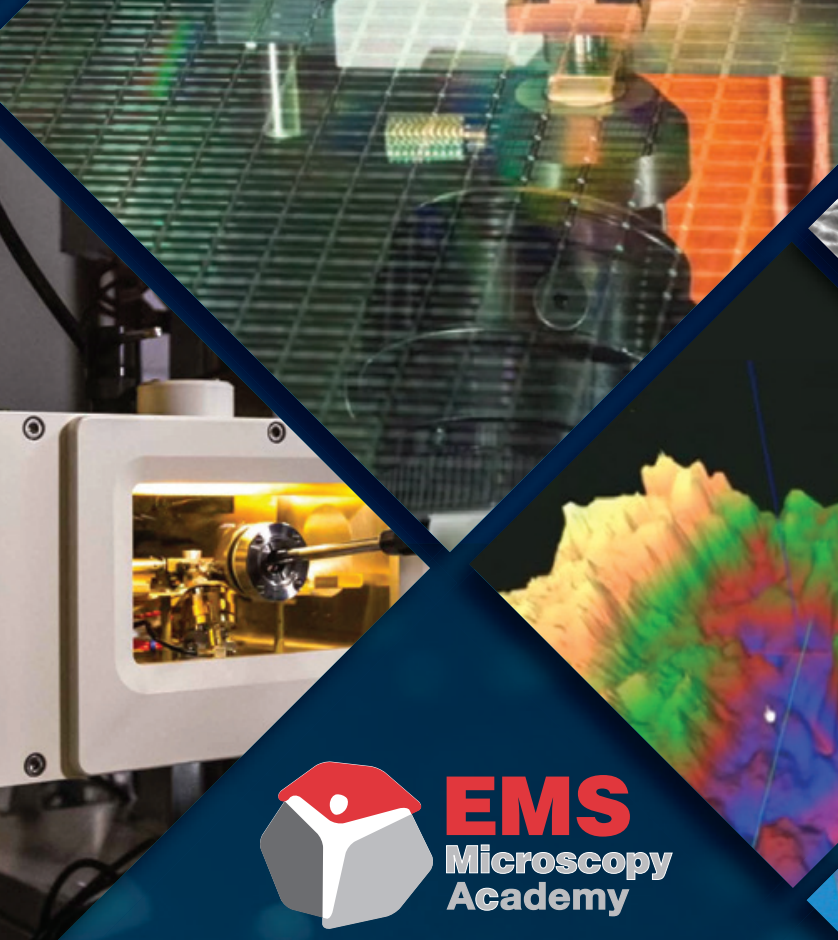

More than just products...

\section{OUR NEW AGADEMY IS NOW OPEN}

Located minutes from Philadelphia, next to our extensive warehouse in Hatfield, PA, we have many offerings led by our certified faculty, including:

\section{MATERIALS ULTRAMICROTOMY} X-RAY MICROANALYSIS

- Ten Educational Workshops

- Corporate Training

- Group Training

- Private Training

- Equipment Demonstrations

\section{www.emsdiasum.com}

Watch for our 2019 schedule coming soon! Plan to sign up and bring your career to the next level!

follow us on...

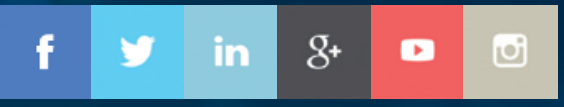


brain of a fruit fly (Drosophila) in a matter of days, which would take years using EM. The imaging produces 3D image tiles, which are then assembled by computer. Using this method the team was able to map more that 40 million synapses in the brain of the fruit fly at nanometer resolution (see Figure 1). The technique yielded similar results when applied to a slice of the brain from mice.

This approach can be performed at speeds that will likely enable comparative studies of neural development, circuit stereotyping, and structural correlations to neural activity or behavior. Combining ExM and LLSM fills a valuable niche between the high throughput of conventional optical imaging of neural anatomy and the ultrahigh resolution of corresponding EM imaging. Assuming the development of fully validated, brain-wide isotropic expansion at ten times or more and sufficiently dense labeling, this combination may enable comparisons throughout the brain of even densely innervated neural circuits across multiple specimens with protein-specific contrast at a resolution of 25 nanometers or better. The future is very bright for this field!

\section{References}

[1] R Gao et al., Science 363(6424) (2019) eaau8302.

[2] The author gratefully acknowledges Drs. Eric Betzig and Ruixuan Gao for reviewing this article.

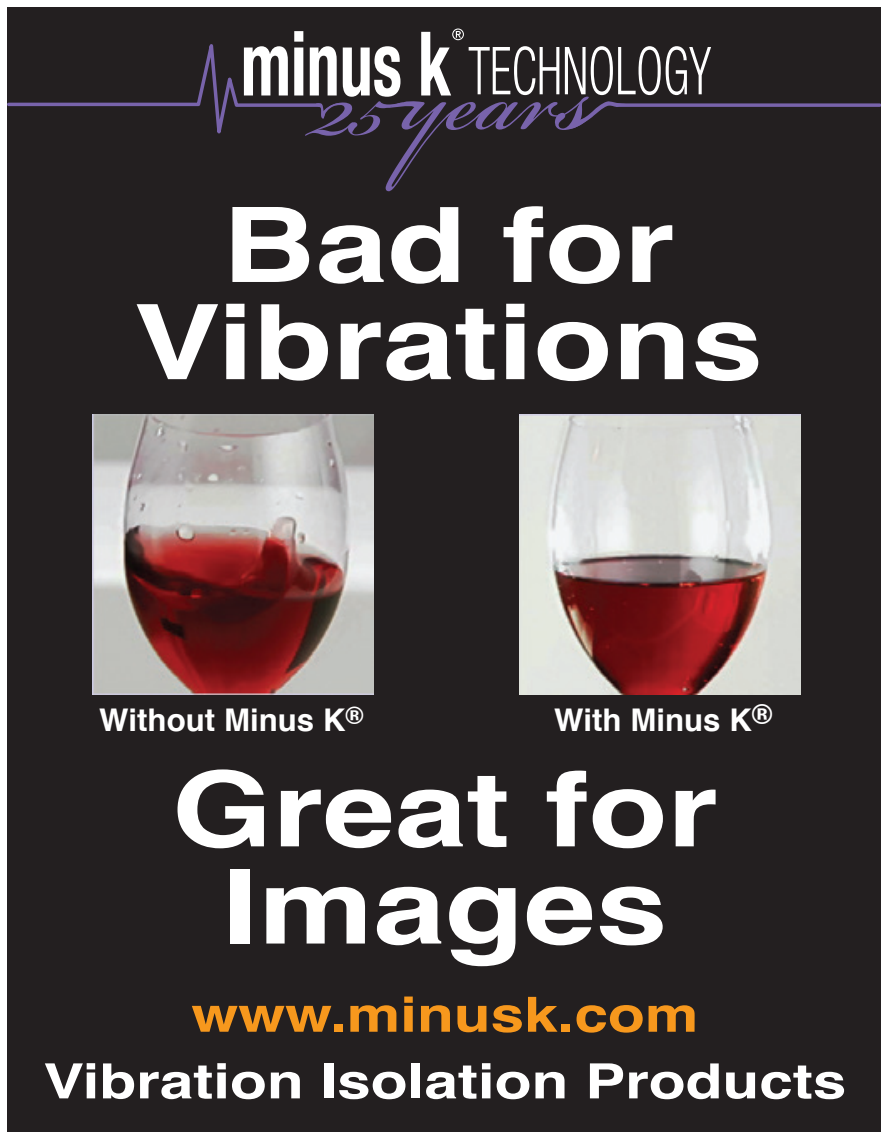

\section{Get Radical (oxygen radicals) with Evactron Plasma Cleaning}

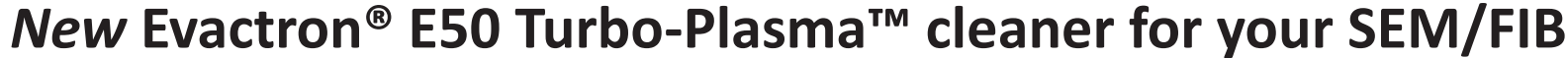

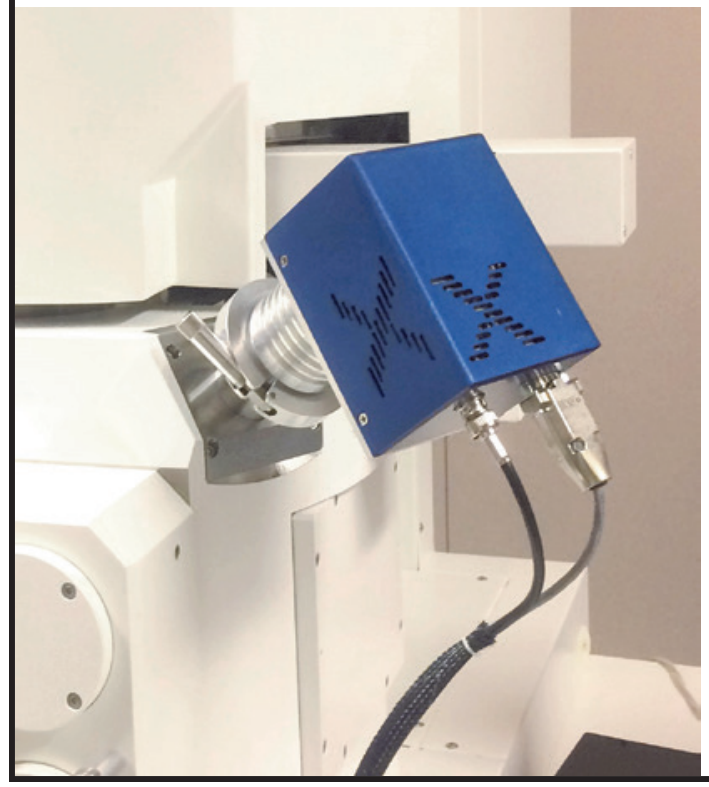

Evactron plasma cleaners generate neutral oxygen radicals from room air. The radicals do the hydrocarbon removal, not the plasma. Do you need:

- 50 Watt max power for fast chemical cleaning

- "POP'M" Ignition at high vacuum-no venting

- Push button or bluetooth GUI operation

- Less downtime for cleaning and pumpdown Lowest cost + best performance $=$ best value

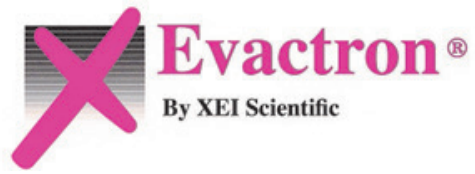

WWW.EVACTRON.COM 1-650-369-0133 


\section{TESCAN S9000X}

Ultimate resolution and maximum throughput

in physical failure analysis of semiconductor

devices and material microanalysis

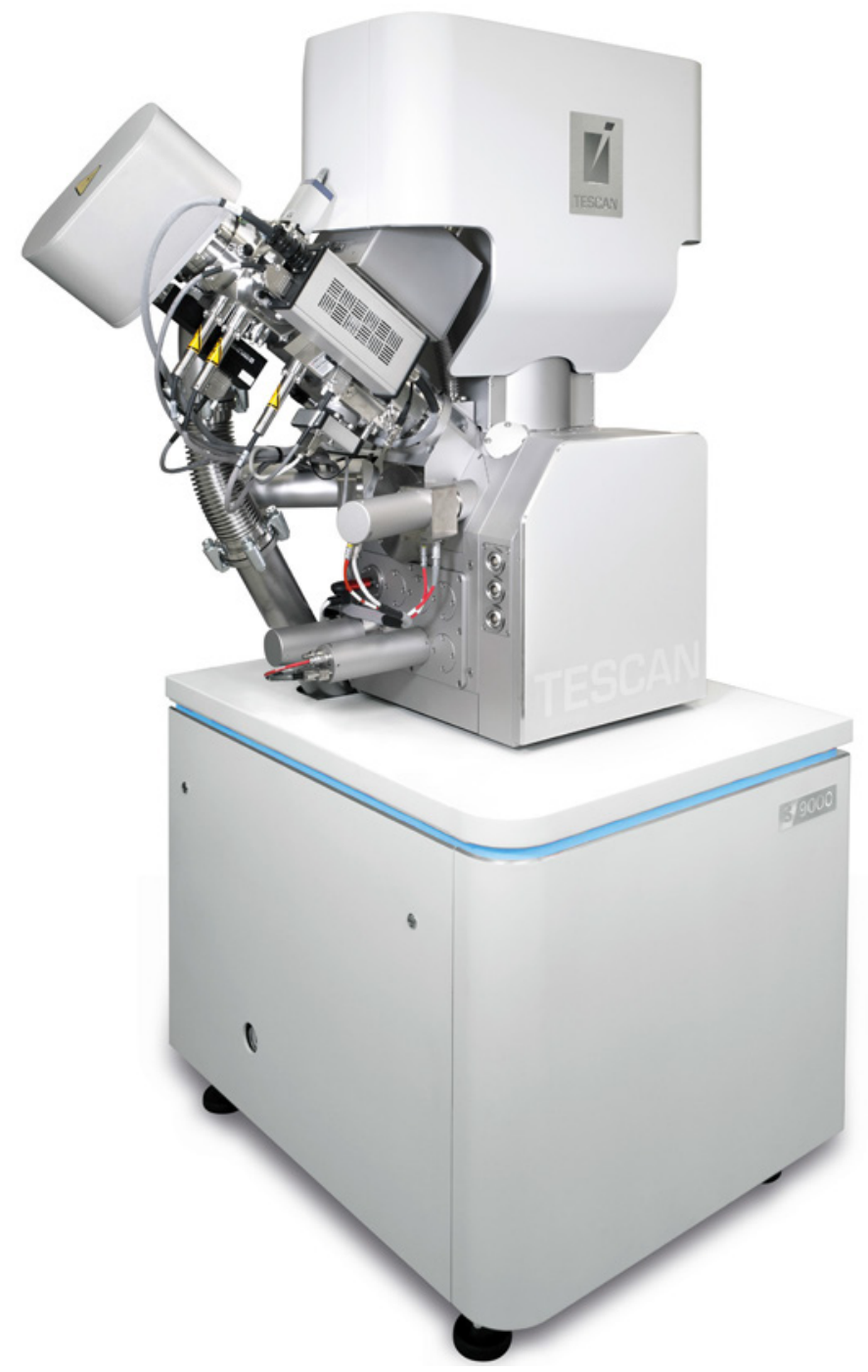

Extremely large cross-section:

New iFIB ${ }^{T^{T M}}$ Xe plasma FIB with high currents up to $2 \mu \mathrm{A}$ and unmatched FoV of $1 \mathrm{~mm}$ redefines conventional large-area cross-sectioning and dramatically decreases sample preparation time.

\section{Extended imaging capabilities:}

Next generation Triglav SEM column with improved and optimized in-beam detection system, and extending imaging capabilities, that now include energy-filtering BSE signal collection for ultimate surface sensitivity in sample characterization.

\section{Applications easier than ever:}

New TESCAN Essence ${ }^{\text {TM }}$ software platform offers a simplified, user-friendly and customizable interface for effortless and maximum control in all applications, regardless the user skill level.
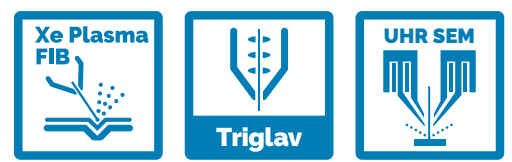

$1.0 \mathrm{~nm}$

لسسسا 10
$0.7 \mathrm{~nm}$

at $15 \mathrm{keV}$
For more information visit www.tescan.com

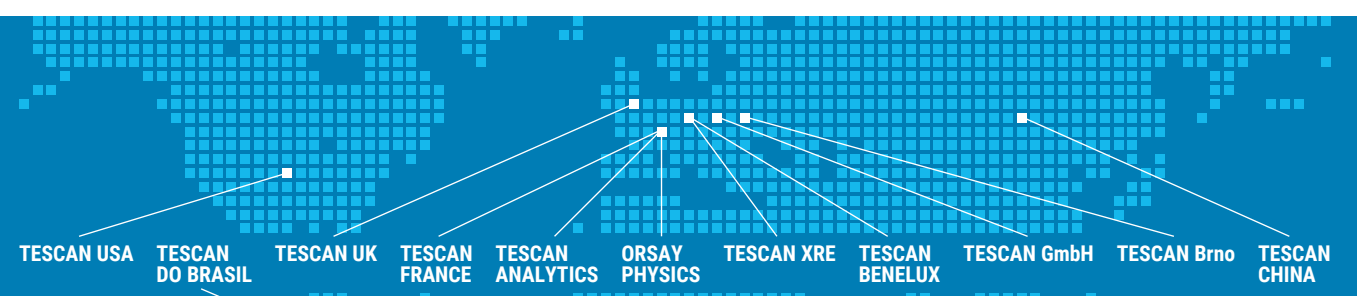

